\title{
Weight expectations, motivations for weight change and perceived factors influencing weight management in young Australian women: a cross-sectional study
}

\author{
Talisha J Holley ${ }^{1}$, Clare E Collins ${ }^{1,2}$, Philip J Morgan ${ }^{2,3}$, Robin Callister ${ }^{2,4}$ and \\ Melinda J Hutchesson ${ }^{1,2, *}$ \\ ${ }^{1}$ School of Health Sciences, Faculty of Health, Advanced Technology Centre (Level 3), University of Newcastle, \\ University Drive, Callaghan, NSW 2308, Australia: ${ }^{2}$ Priority Research Centre in Physical Activity and Nutrition, \\ University of Newcastle, Callaghan, New South Wales, Australia: ${ }^{3}$ School of Education, Faculty of Education and \\ Arts, University of Newcastle, Callaghan, New South Wales, Australia: ${ }^{4}$ School of Biomedical Sciences and \\ Pharmacy, Faculty of Health and Medicine, University of Newcastle, Callaghan, New South Wales, Australia
}

Submitted 10 April 2014: Final revision received 4 January 2015: Accepted 19 February 2015: First published online 6 May 2015

\begin{abstract}
Objective: To examine young Australian women's weight expectations, motivations for weight change and perceived factors influencing weight management, and to determine if these factors differ by age, BMI, marital status, education or income. Design: Cross-sectional study. An online survey captured respondents' weight, height, ideal weight, main reasons for wanting to change their weight and challenges to managing their weight.

Setting: Online survey in Australia.

Subjects: Six hundred and twenty women aged 18-30 years currently living in Australia who completed the survey between 31 July and 30 September 2012. Results: Approximately half of participants (53.1\%) were a healthy weight, $25.2 \%$ overweight and 19.0\% obese. Women unhappy at their current weight (78.1\%) reported a median ideal weight $-12.3 \%$ less than their current weight. The key motivators for weight change were to improve health $(24.4 \%$, ranked 1$)$, feel better in oneself (22.3\%) and improve self-confidence (21.5\%). Lack of motivation, time constraints because of job commitments and cost were the most commonly reported factors influencing weight management. Age, BMI, marital status, education and income were found to influence weight expectations, motivations for weight change and/or factors perceived to influence weight management.

Conclusions: The findings suggest potential implications for weight management interventions and public health messaging targeting young women, to improve long-term health outcomes. Strategies that promote the health benefits of physical activity and healthy eating, feeling better about oneself and improved selfconfidence, and address the main factors influencing weight management including lack of motivation, time constraints and cost, may be used to engage this target group.
\end{abstract}

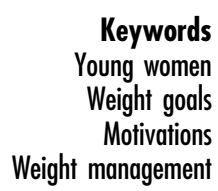

Weight gain among young women is a major public health concern $^{(1)}$. A longitudinal study in Australian adults (AUSDIAB) reported that women aged $25-34$ years gained an average of $6.6 \mathrm{~kg}$ over a 12-year period and this life stage had the highest rate of weight gain among the women studied $^{(2)}$. Similarly, in a US 10-year prospective study of young adults (18-30 years), Caucasian women experienced a mean weight gain of $6.9 \mathrm{~kg}^{(3)}$. Weight gain during young adulthood and the development of obesity among young women are associated with an increased risk of depression $^{(4,5)}$, infertility ${ }^{(5,6)}$, pregnancy complications $^{(5,6)}$ and chronic conditions in adulthood, including type 2 diabetes $^{(5-7)}, \operatorname{CVD}^{(5,6,8)}$ and certain cancers ${ }^{(5,6,9)}$.

Interventions to prevent weight gain and obesity among young women have the potential to significantly impact health outcomes and reduce health-care costs at the population level. However, traditional behavioural approaches to weight control may be ineffective for young women, with research suggesting lower rates of recruitment and attendance, higher attrition and less successful weight-loss outcomes ${ }^{(10)}$ Furthermore, recent systematic reviews of weight management interventions in young 
adults $^{(11-13)}$, including young women specifically ${ }^{(14)}$, have found insufficient evidence to guide intervention design and delivery in this area. One review concluded that there appear to be preferences for intervention by gender ${ }^{(13)}$. Therefore in order to inform the design of interventions that are capable of engaging young adults, greater knowledge of the expectations of weight management programmes, motivations for weight loss, and barriers to and facilitators of behaviour change for each gender is required.

Several studies have shown that adults' weight-loss expectations are unrealistic. Despite initial weight-loss recommendations of $5-10 \%^{(15,16)}$, research suggests that adults expect to lose $21-28 \%$ of their starting weight within the first year of treatment ${ }^{(17-20)}$, with desired weight losses as high as $34 \%{ }^{(18,20)}$. Most of these studies examined weight-loss expectations among middle-aged cohorts ${ }^{(18-28)}$ or the general population ${ }^{(17,29-34)}$. A small $(n$ 44) Italian study of 18-35-year-old women reported that non-obese women would need to lose $18 \%$ and obese women $23 \%$ of their current weight to reach their ideal weight ${ }^{(35)}$. This suggests that young women's weight-loss expectations may be unrealistic, but this finding needs to be confirmed in a larger, more diverse sample of young women.

Previous research has identified that key motivations for weight loss include physical appearance and health $^{(17,21,30,36-39)}$ and wanting to feel better about oneself $^{(30,36,38,39)}$. Studies have also found that motivations for weight loss may differ according to sex and age ${ }^{(17,39)}$. Women (mean age of 38.2 years) who enrolled in a weight management intervention were more likely to report appearance rather than improving health as the key motivation for enrolment, when compared with males ${ }^{(17)}$. Findings from the US National Weight Control Registry suggest that young adults (18-35 years) who maintained a weight loss for at least 1 year were more likely to report improved appearance or social factors as their primary motivators for weight loss and less likely to report health concerns as their motivation, when compared with older adults (36-50 years) ${ }^{(39)}$. These findings suggest that young women have different motivations for wanting to control their weight; however, these studies were restricted to individuals already enrolled in a weight-loss intervention or who had achieved successful weight-loss maintenance and therefore may not be representative of young women generally.

Many personal, social and environmental factors have been suggested to influence adults' ability to manage their weight, engage in physical activity and/or consume a healthy diet; these include insufficient time ${ }^{(40-44)}$ and lack of motivation ${ }^{(40,42,44,45)}$, partner support ${ }^{(44)}$ or knowledge $^{(44)}$. Only one study has specifically explored the factors that influence young women's ability to manage their weight, with lack of motivation, time constraints due to job commitments and cost as the most common perceived factors limiting effective weight management in
445 young Australian women ${ }^{(46)}$. However, that study was undertaken over 10 years ago and it is currently unknown if the present generation of young women face the same barriers to managing their weight.

Therefore, to better inform the design of weight management interventions for young women, the aim of the present cross-sectional study was to examine young (18-30 years) women's weight expectations, their key motivations for weight change and factors they perceive to influence weight management. The secondary aim was to determine whether these areas differed by age, BMI, marital status, education or income.

\section{Experimental methods}

\section{Participants and setting}

Data for the present cross-sectional study were collected online to inform the design of a weight management intervention for young women. Women aged 18-30 years currently living in Australia were eligible to participate in the study. A cut-off of 30 years of age was chosen for the intervention as this is approximately the median age at which women in Australia give birth to their first child ${ }^{(47)}$ and the intervention aims to target women prior to childbearing.

A convenience sample of young women was recruited initially via advertisements on the University of Newcastle's website and social networking pages (Facebook, Twitter). An email was also sent to university staff and student mailing lists. Snowball sampling, whereby participants were asked to share the survey link with others in the target group via email and/or social networking sites, was used to increase the size and characteristics of the sample. The recruitment materials requested women to participate in a survey to help the researchers design a weight-loss programme specifically for them. Participants had the option of entering a prize draw to win one of ten gift vouchers for a shopping centre (four vouchers), a beauty therapist (three vouchers) or the cinema (three vouchers), valued at \$AU 150 each. The prize draw was highlighted in the recruitment materials.

Links to the online survey were provided in the advertisements and emails. The first page of the online survey included an information statement that outlined the purpose of the study. Individuals who provided consent then completed an eligibility screen as well as completing the survey. The survey was available between 31 July and 30 September 2012. Ethics approval was obtained from the University of Newcastle Human Research Ethics Committee.

\section{Data collection}

All data were collected via the online survey, which was developed and managed using Survey Monkey (www. surveymonkey.com.au), an online survey management system. Survey responses were sent to the researchers' 
Survey Monkey account via a secure, encrypted connection; only the chief investigator (M.J.H.) had access to the password-protected Survey Monkey account. Respondents' contact details, collected for the purposes of the prize draw, were stored separately from the survey data; therefore survey question responses were anonymous.

The survey was pilot tested with young women ( $n$ 5) prior to implementation, to ensure that questions were clearly understood, could be completed within the suggested time frame and were appropriately structured for statistical analysis. These young women completed the survey and then provided feedback to the researchers via a telephone interview. The final survey consisted of thirty-nine questions addressing sociodemographic characteristics, ideal weight, expectations of a weight-loss programme for young women, weight and weight-control behaviours, as well as key motivations and potential factors influencing weight management. The survey was displayed over twenty-eight pages, ranging from one to six questions per page, and took approximately $15 \mathrm{~min}$ to complete.

\section{Sociodemographic characteristics}

Demographic data were collected including date of birth, marital status, highest level of education and income. The questions were consistent with the Australian Bureau of Statistics' Census of Population and Housing ${ }^{(48)}$ to allow comparison of the sample and determine how representative it was of the young Australian female population. Age was categorized into two groups: 18-24 years and 25-30 years ${ }^{(49)}$. Marital status was collapsed into two categories: married/de facto or single (never married, separated, divorced or widowed). Individual gross income was collapsed into three categories: lower (\$AU 0-299/week), middle (\$AU 300-999/week) or higher ( $\geq$ \$AU 1000/week). Education levels were collapsed into five categories: school certificate (Year 10 or equivalent); higher school certificate (Year 12 or equivalent); trade/apprenticeship/certificate/ diploma; university degree; and higher university.

\section{Weight status}

Participants were asked to report their height (in centimetres) and weight (in kilograms), and BMI (weight/ height ${ }^{2} ; \mathrm{kg} / \mathrm{m}^{2}$ ) was calculated. Women were categorized as underweight $\left(\mathrm{BMI}<18.5 \mathrm{~kg} / \mathrm{m}^{2}\right)$, healthy weight $(\mathrm{BMI}=$ $\left.18.5-24.99 \mathrm{~kg} / \mathrm{m}^{2}\right)$, overweight $\left(\mathrm{BMI}=25 \cdot 0-29.99 \mathrm{~kg} / \mathrm{m}^{2}\right)$ or obese $\left(\mathrm{BMI} \geq 30 \cdot 0 \mathrm{~kg} / \mathrm{m}^{2}\right)^{(50)}$.

\section{Weight expectations}

To determine 'satisfaction at current weight', participants were asked: 'Are you happy at your current weight?' Respondents who answered 'no' were asked 'How much would you like to weigh in kilograms?' Responses were re-coded to the nearest $0 \cdot 1 \mathrm{~kg}$ and expressed as ideal weight. Ideal BMI was calculated using self-reported height and the ideal weight reported by respondents ${ }^{(50)}$.
The absolute and percentage differences between ideal and current weight were used to calculate the change in weight required to achieve participants' ideal weight. Participants who reported an ideal weight less than $30 \mathrm{~kg}$ or greater than $140 \mathrm{~kg}^{(51)}$, and an ideal BMI less than $10 \mathrm{~kg} / \mathrm{m}^{2}$ or greater than $55 \mathrm{~kg} / \mathrm{m}^{2}$, were considered implausible and therefore data were treated as missing ( $n$ 10) for the associated variables.

\section{Motivations for weight change}

Respondents were asked to rank from 1 to 6 the following reasons for wanting to change their weight: 'to improve my self-confidence', 'to feel more attractive', 'to change my appearance', 'to wear the clothes I want', 'to improve my health' and 'to feel better in myself/lift my mood', whereby $1=$ 'most important' and $6=$ 'least important'. This item was developed by the researchers based on a literature review to determine potential motivators for weight control in this target group.

\section{Perceived factors influencing weight management}

Perceived factors influencing weight management in relation to physical activity/exercise and eating habits were assessed using twenty items (see list in Table 4). Participants were asked to indicate the degree to which each item influenced their ability to maintain their weight at the desired level using a 5-point Likert scale. The items were devised from a previous study that based the factors on a literature review of perceived factors influencing weight management in other population groups ${ }^{(46)}$. Responses were collapsed into three categories (1-2, does not influence; 3, a moderate influence; 4-5, a major influence) for analysis.

\section{Statistical analysis}

Data analysis was conducted using the JMP statistical software package version 9.0. The Shapiro-Wilk test was performed for all continuous data to determine normality of distribution. No continuous data were normally distributed; therefore non-parametric tests were used for all analyses. $P$ values less than 0.01 were considered statistically significant due to the multiple comparisons made, to therefore reduce the likelihood of type 1 error. Results are expressed as medians and interquartile ranges (IQR) for continuous data and as percentages and numbers for categorical data. Descriptive statistics were used to describe participants' sociodemographic characteristics, weight expectations, motivations for weight change and perceived factors influencing weight management. Wilcoxon rank-sum tests were conducted to determine differences in ideal weight between age groups and marital status categories. The Kruskal-Wallis test was used to assess differences in ideal weight between BMI, education and income categories. Pearson's $\chi^{2}$ test was used to investigate differences in satisfaction at current weight, 
motivations for weight change and perceived factors influencing weight management between all subgroups (age, BMI, marital status, education and income).

\section{Results}

Of the 798 individuals who consented, 742 met the inclusion criteria, of whom 647 completed the full survey (Fig. 1). A total of 620 young women were included in the analysis. Pregnant and/or breast-feeding women ( $n$ 21) were excluded as weight status was unlikely to indicate their usual weight ${ }^{(28)}$. Duplicate responses were excluded ( $n$ 6) based on a comparison of IP addresses used during the survey period, with the most recent responses excluded.

\section{Sociodemographic characteristics and weight status}

The sociodemographic profile of the young women who were included in the analysis is summarized in Table 1. The median age was $24 \cdot 0$ (IQR 21.0, 27.0) years. More participants were aged 18-24 years (57.7\%), single $(65.5 \%)$, and reported the higher school certificate $(37.9 \%)$ or university $(34.0 \%)$ as the highest level of education. Similar proportions of participants reported lower (40.6\%) and middle (37.6\%) incomes.

The median BMI of the sample was $24 \cdot 0$ (IQR 21.6, 28.7) $\mathrm{kg} / \mathrm{m}^{2}$. Just over half of participants $(53.1 \%)$ were in the healthy weight range, $25 \cdot 2 \%$ were overweight and $19.0 \%$ obese. Due to the very small number of underweight participants ( $n$ 17), this group was excluded from all further BMI analyses. BMI differed by age, education level and income. Younger respondents (18-24 years) reported a lower median weight (65.0 (IQR 59.0, 76.0) kg; $P=0.001$ ) and BMI $(23.7$ (IQR $\left.21.3,27 \cdot 8) \mathrm{kg} / \mathrm{m}^{2} ; P=0.004\right)$ compared with women aged 25-30 years (68.0 (IQR 62.0, 80.6) kg and $25 \cdot 0$ (IQR 22.2, 29.3) kg/m², respectively). Participants with trade/apprenticeship/certificate/diploma qualifications reported significantly higher median BMI (26.8 (IQR 22.8, $\left.30.4) \mathrm{kg} / \mathrm{m}^{2} ; P=0.006\right)$ compared with those having a university education (23.7 (IQR 21.5, 27.4) $\mathrm{kg} / \mathrm{m}^{2}$ ). Participants with a middle income reported a significantly higher median BMI (24.5 (IQR 22.3, 29.8) kg/m²) than participants with lower $(23 \cdot 8$ (IQR $21 \cdot 2,27 \cdot 8) \mathrm{kg} / \mathrm{m}^{2}$ ) and higher incomes $(23 \cdot 3$ (IQR $\left.21 \cdot 6,27 \cdot 2) \mathrm{kg} / \mathrm{m}^{2} ; P=0 \cdot 004\right)$.

Comparison with 2011 Australian Census data indicated that the sample was reasonably representative of the population of women of the same age in Australia. There was some response bias in terms of over-representation of those with higher education levels ${ }^{(52)}$, lower incomes ${ }^{(53)}$, as well as the number of single women ${ }^{(54)}$. Comparison with the Australian Health Survey data indicated that the sample also had a higher proportion of overweight women (25.2\%) compared with Australian females aged $18-34$ years $(18.7 \%)^{(55)}$.

\section{Weight expectations}

Weight expectations, and differences by age, BMI, marital status, education and income, are reported in Table 2 . The majority $(78.1 \%)$ of young women reported they were

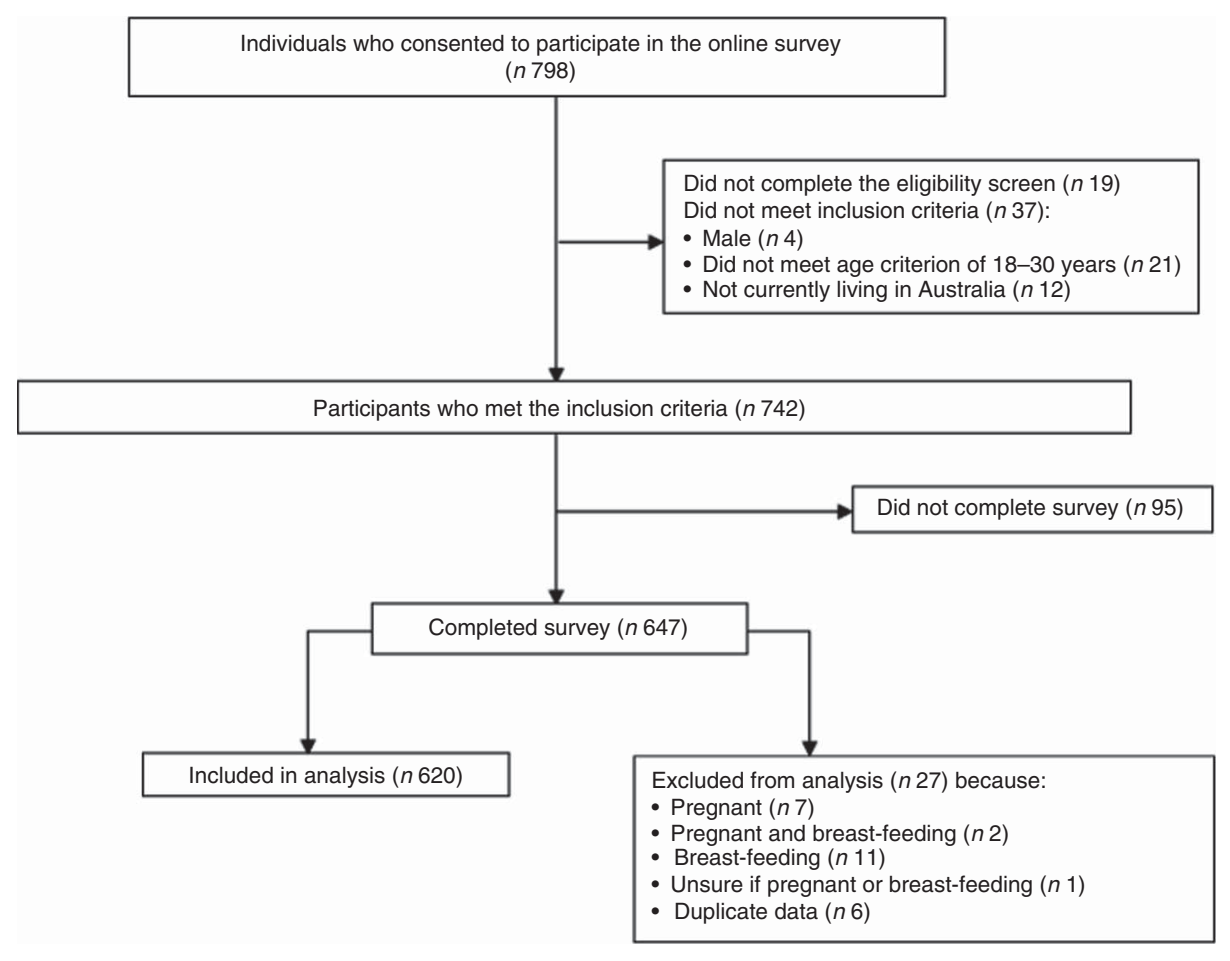

Fig. 1 Participant recruitment and eligibility 
Table 1 Sociodemographic characteristics and weight status of young women ( $n$ 620) who completed the online survey and met the inclusion criteria, Australia, 31 July-30 September 2012

\begin{tabular}{|c|c|c|}
\hline & Median or $\%$ & IQR or $n$ \\
\hline \multicolumn{3}{|l|}{ Sociodemographic characteristics } \\
\hline Age (years) & 24.0 & $21 \cdot 0,27 \cdot 0$ \\
\hline \multicolumn{3}{|l|}{ Age group } \\
\hline $18-24$ years & $57 \cdot 7$ & 358 \\
\hline $25-30$ years & $42 \cdot 3$ & 262 \\
\hline \multicolumn{3}{|l|}{ Country of birth } \\
\hline Australia & 89.2 & 553 \\
\hline \multicolumn{3}{|l|}{ Languages spoken at home } \\
\hline English only & $92 \cdot 6$ & 574 \\
\hline Other & 7.4 & 46 \\
\hline \multicolumn{3}{|l|}{ Marital status } \\
\hline Married/de facto & 34.5 & 214 \\
\hline $\begin{array}{l}\text { Never married/separated/ } \\
\text { divorced/widowed }\end{array}$ & $65 \cdot 5$ & 406 \\
\hline \multicolumn{3}{|l|}{ Highest education level } \\
\hline School certificate & 2.4 & 15 \\
\hline Higher school certificate & 37.9 & 235 \\
\hline $\begin{array}{l}\text { Trade/apprenticeship/certificate/ } \\
\text { diploma }\end{array}$ & $17 \cdot 0$ & 105 \\
\hline University degree & 34.0 & 211 \\
\hline Higher university degree & 8.7 & 54 \\
\hline \multicolumn{3}{|l|}{ Individual income } \\
\hline Lower (\$AU 0-299/week) & $40 \cdot 6$ & 252 \\
\hline Middle (\$AU 300-999/week) & 37.6 & 233 \\
\hline Higher ( $\geq \$ A U$ 1000/week) & $18 \cdot 1$ & 112 \\
\hline \multicolumn{3}{|l|}{ Weight status } \\
\hline Current weight (kg) & $67 \cdot 0$ & $60.0,78.9$ \\
\hline Current height $(\mathrm{cm})$ & $166 \cdot 0$ & $161.0,171.0$ \\
\hline BMI $\left(\mathrm{kg} / \mathrm{m}^{2}\right)$ & $24 \cdot 0$ & $21 \cdot 6,28 \cdot 7$ \\
\hline \multicolumn{3}{|l|}{ BMI category } \\
\hline Underweight & $2 \cdot 7$ & 17 \\
\hline Healthy weight & 53.1 & 329 \\
\hline Overweight & $25 \cdot 2$ & 156 \\
\hline Obese & $19 \cdot 0$ & 118 \\
\hline
\end{tabular}

$I Q R$, interquartile range.

unhappy at their current weight. A significantly higher proportion of women who were obese (99.1\%) or overweight $(92.3 \%)$ reported they were unhappy at their current weight compared with healthy weight women (65.3\%; $P<0.001)$. There were no differences in the number of participants who were unhappy at their current weight by age, marital status, income or education.

Among the respondents who reported they wished to change their weight ( $n$ 484), all reported an ideal weight less than their current weight (i.e. wanting to lose weight). The median ideal weight was $60 \cdot 0$ (IQR $55 \cdot 0,67 \cdot 0$ ) $\mathrm{kg}$ and the median ideal BMI was $22 \cdot 1$ (IQR 20.3, 24.0) $\mathrm{kg} / \mathrm{m}^{2}$. This required a median weight change of $-8 \cdot 0$ (IQR $-5 \cdot 0$, $-15 \cdot 0$ ) $\mathrm{kg}$ or $-12 \cdot 3$ (IQR $-7 \cdot 9,-18 \cdot 8$ ) \% to achieve their ideal weight. Median ideal weight (healthy weight, $57.0 \mathrm{~kg}$; overweight, $65.0 \mathrm{~kg}$; obese, $70.0 \mathrm{~kg} ; P<0.001$ ) and median ideal BMI (healthy weight, $20 \cdot 3 \mathrm{~kg} / \mathrm{m}^{2}$; overweight, $23.1 \mathrm{~kg} / \mathrm{m}^{2}$; obese, $\left.25.4 \mathrm{~kg} / \mathrm{m}^{2} ; P<0.001\right)$ increased significantly with increasing BMI category; and single women reported a significantly $(P=0 \cdot 01)$ lower median ideal BMI $\left(22.0 \mathrm{~kg} / \mathrm{m}^{2}\right)$ than women who were married or in a de facto relationship $\left(22.5 \mathrm{~kg} / \mathrm{m}^{2}\right)$.
As expected, obese women reported significantly $(P<0.001)$ higher median absolute and percentage weight changes to achieve their ideal weight, $-26 \cdot 0$ (IQR $-18 \cdot 0$, -33.9) $\mathrm{kg}$ and $-27 \cdot 8$ (IQR -19.6, -33.7) \%, compared with overweight and healthy weight women (Table 2). The weight change required to achieve ideal weight also varied by education and income levels. Higher university degree women reported the lowest median absolute and percentage weight change to achieve ideal weight: -5.5 (IQR -4.0, -11.8) $\mathrm{kg}$ and -8.5 (IQR -6.9, -16.0)\% $(P=0.001$ and $P<0.001)$, respectively. Higher-income respondents reported significantly $(P<0.001)$ lower median absolute and percentage weight change to achieve ideal weight, $-6 \cdot 0$ (IQR -4.0, -10.3) $\mathrm{kg}$ and -9.1 (IQR -6.6, $-14 \cdot 2$ ) \%, compared with middle income earners (Table 2).

\section{Motivations for weight change}

Overall motivations for weight change, and difference by age, BMI, marital status, education and income, are summarized in Table 3 and Supplemental Table 1 (see online supplementary material). Almost one-quarter of participants (24.4\%) ranked 'improve health' as their most important reason to change their weight, followed by 'feel better in myself/lift my mood' (22.3\%) and 'improve selfconfidence' (21.5\%; Table 3). Notably, almost half of all participants $(47.8 \%)$ rated 'to feel better in myself/lift my mood' as the first or second most important reason for wanting to change their weight. The least important reasons (ranked sixth) for wanting to change their weight were 'to wear the clothes I want' $(32.7 \%)$ or 'to change appearance' (25.5\%).

There were no significant differences reported for motivations for weight change by age or marital status. Obese respondents were significantly less likely $(P=0 \cdot 004)$ to rank 'to feel more attractive' as the most important reason for wanting to change their weight (10.5\%) compared with overweight (15.2\%) and healthy weight (14.7\%) respondents. Also, they were more likely $(P<0.001)$ to rank 'to improve health' as the most important reason (39.5\%) for weight change compared with those who were overweight $(23.9 \%)$ or a healthy weight $(17.1 \%)$. Individuals with lower weekly incomes were more likely to rank 'to improve self-confidence' as the most important reason for changing their weight $(27.7 \%)$ compared with those of middle (19.2\%) or higher incomes $(13.1 \% ; P=0.007)$. Similarly, those with lower education levels, such as a school certificate $(38.5 \%)$, were more likely to rank to improve self-confidence' as the most important reason for weight loss compared with those of higher education levels such as holding a university degree $(13.8 \% ; P=0.009)$.

\section{Perceived factors influencing weight management: physical activity}

Table 4 summarizes the proportion of participants who rated the influence of each item relating to physical activity 


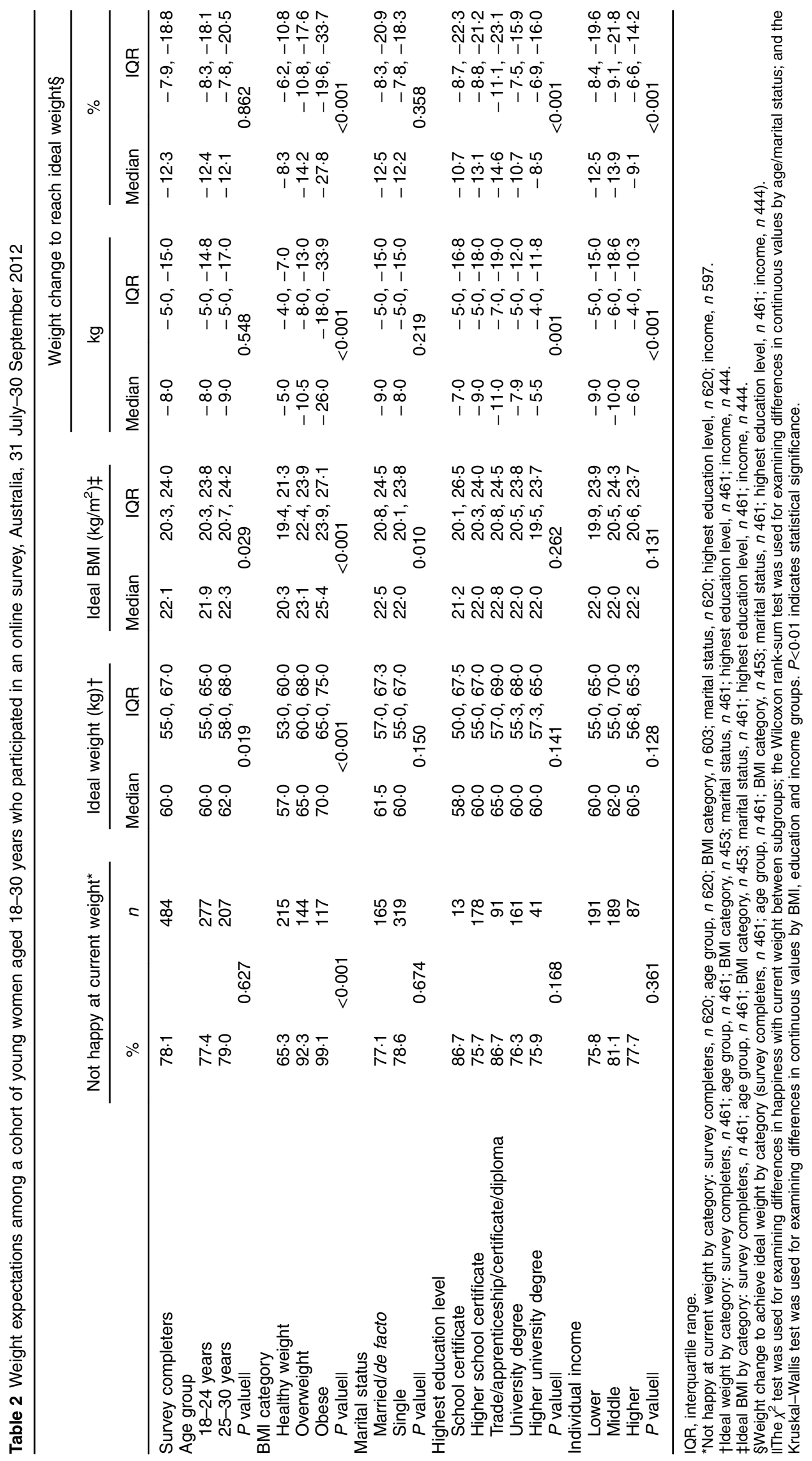




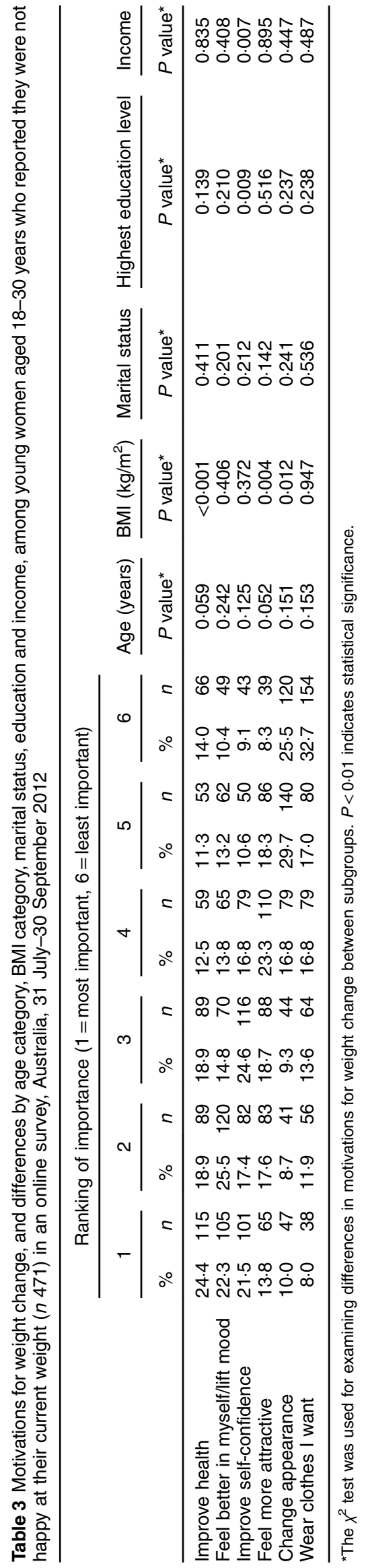

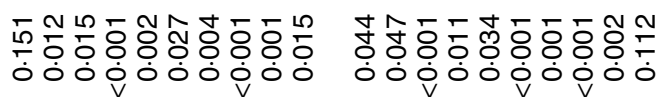

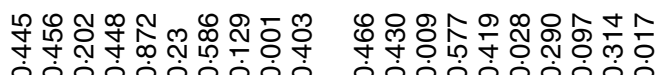

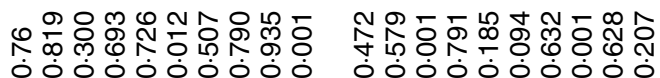

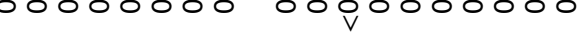

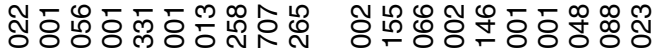

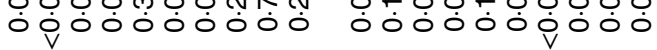

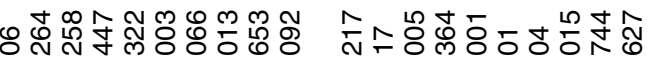
O000000000 0000000000

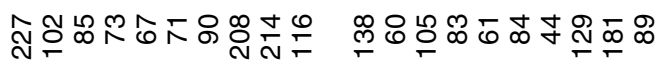

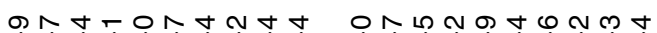

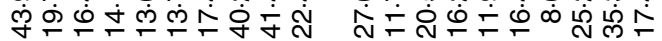

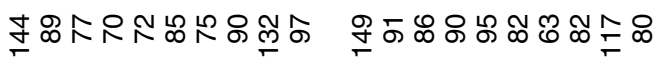

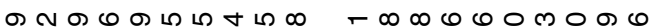

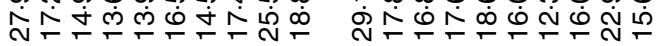

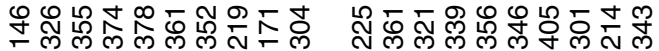

$n-\Lambda m-\infty-4-\infty$ の

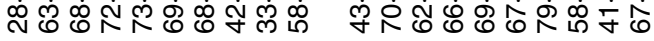

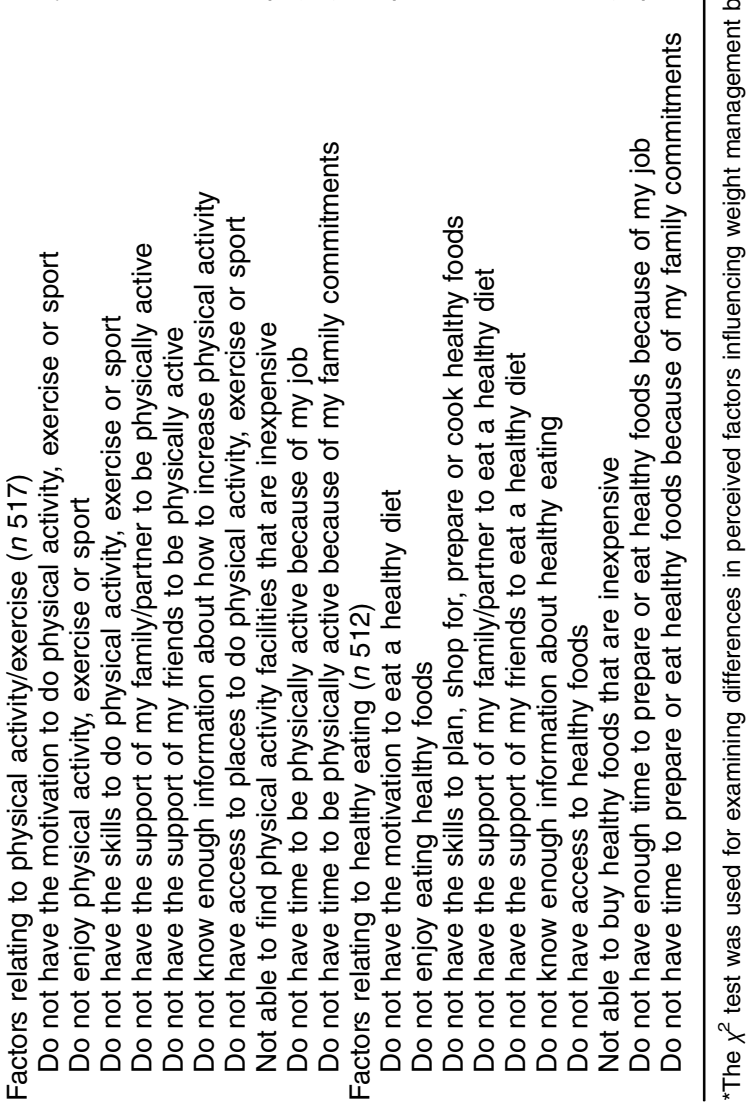


on their ability to maintain weight at a desired level. Combining moderate and major influence response categories, the majority of respondents $(71 \cdot 8 \%)$ reported lack of motivation ('do not have the motivation to do physical activity, exercise or sport') as the main influence relating to physical activity. This was followed by environmental factors such as time (66.9\%; 'do not have the time to be physically active because of my job') and cost (57.6\%; 'not able to find physical activity facilities that are inexpensive').

The factors perceived to influence young women's ability to maintain their weight at the desired level relating to physical activity differed by age, BMI, education, income and marital status (see online supplementary material, Supplemental Table 2). Only $31.2 \%$ of respondents felt lack of knowledge about how to increase physical activity influenced their weight management, with those aged 18-24 years more likely to report this as an influence $(35 \cdot 1 \%)$ compared with those aged $25-30$ years (23.4\%; $P=0.003)$. In addition, lack of knowledge ('do not know enough information about how to increase physical activity') was more likely to be a moderate or major influence as BMI increased (healthy weight, 23.5\%; overweight, $31 \cdot 1 \%$; obese, $46.4 \% ; P=0 \cdot 001$ ).

A higher proportion of participants who were married or in a de facto relationship cited lack of time to be physically active due to family commitments as a major influence on their ability to manage their weight $(31.5 \%)$ compared with single participants $(17.5 \% ; P=0.001)$.

Lack of time to be physically active due to job commitments was reported as a major influence by a greater proportion of women with higher levels of education (school certificate, $21.4 \%$; higher school certificate, $34.2 \%$; trade/apprenticeship/certificate/diploma, 34.8\%; university, $50.0 \%$; higher university, $61.0 \% ; P=0.001$ ) as well as higher income earners (lower, 32.2\%; middle, $45.9 \%$; higher, $54.4 \% ; P=0.001)$.

Lack of social support from family to be physically active was more likely to be reported as an influence by obese women, compared with those of healthy weight (healthy weight, $8.3 \%$; overweight, $17.0 \%$; obese, $25.5 \%$; $P=0.001)$. Lack of social support from both family and friends was more likely to influence women of lower income $(17.3 \%$ and $14.9 \%$ major influence) compared with higher income earners $(2.2 \%$ and $4.4 \% ; P<0.001)$. Obese women were more likely to report lack of enjoyment of physical activity (54.5\%) compared with healthy weight (31.2\%) and overweight women (32.8\%; $P<0 \cdot 001)$. A higher proportion of lower-income women reported cost $(68.7 \% ; P<0.001)$ and lack of access ( $40.6 \% ; P=0.004$ ) compared with those with middle and higher incomes.

\section{Perceived factors influencing weight management: bealthy eating}

Table 4 summarizes the proportion of participants who rated the influence of each item relating to healthy eating on their ability to maintain weight at a desired level. For influences relating to healthy eating, $58.2 \%$ of participants reported not having the time ('do not have time to prepare or eat healthy foods because of my job') whereas $56.1 \%$ rated lack of motivation ('do not have the motivation to eat a healthy diet') and $41.2 \%$ cited cost ('not able to buy healthy foods that are inexpensive') as moderate and major influences.

The factors perceived to influence young women's ability to maintain their weight at the desired level relating to healthy eating differed by age, BMI, education, income and marital status (see online supplementary material, Supplemental Table 3). Although just over one-quarter of respondents reported that not having the skills to plan, shop for, prepare or cook healthy foods influenced their ability to manage their weight, significantly higher proportions of 18-24-year-olds (24.5\%), single women $(25.7 \%)$ and those with a higher school certificate $(27.4 \%)$ reported it was a major influence compared with 25-30-year-olds (15.1\%; $P=0.005)$, women who were married or in a de facto relationship (11.0\%; $P<0.001)$ and those of other education levels $(P=0.009)$, respectively.

A higher proportion of 18-24-year-olds reported that they did not have the support of friends to eat a healthy diet compared with women aged $25-30$ years $(37 \cdot 4 \%$ vs. $21.1 \% ; P<0.001)$. Obese women were more likely to report not having family/partner support to eat a healthy diet as a major influence $(28.2 \% ; P=0.002)$ compared with overweight $(15.8 \%)$ and healthy weight women (11.5\%).

As BMI category increased, a greater proportion of women said lack of access to healthy foods (healthy weight, $6.9 \%$; overweight, $9.0 \%$; obese, $12.7 \%$; $P<0.001$ ) as well as not knowing enough information about healthy eating (healthy weight, $14.6 \%$; overweight, $15.0 \%$; obese, $23.6 \% ; P=0.001)$ were major influences. As income increased, a significantly lower proportion of women said a lack of access to healthy foods (lower, $12.4 \%$; middle, $7.3 \%$; higher, $2.2 \% ; P=0.001)$ as well as having knowledge about healthy foods (lower, 20.0\%; middle, $17.6 \%$; higher, $5.6 \%$; $P<0.001)$ was a major influence.

Single women were more likely to report the cost of healthy foods (28.4\%) as a major influence compared with those who were married or in a de facto relationship (19.3\%; $P=0.008)$, as did women of lower incomes $(32.4 \%)$ compared with those of higher incomes (11.1\%; $P<0.001)$. Those on higher incomes were significantly more likely to report time due to job commitments as a major influence $(40.4 \%)$ compared with those on lower incomes $(26.2 \% ; P=0.002)$. A higher proportion of obese women reported lack of motivation to eat a healthy diet (40.0\%; $P=0.002$ ) as a major influence compared with overweight and healthy weight individuals $(26.3 \%$ and $21 \cdot 8 \%$, respectively). 


\section{Discussion}

The present study identified that, overall, young women have unrealistic weight-loss expectations, are motivated to change their weight for their health and to improve their self-confidence, and find motivation, time constraints and cost to be the major factors that they report as influencing their lifestyle behaviours. However, the study also highlighted a number of differences for weight-loss expectations, key motivators for weight change and perceived factors influencing weight management by BMI status, age and socio-economic status (i.e. marital status, income and education). These findings suggest that a 'one size fits all approach' to weight management may not be effective for all young women. Greater attention should be given to these differing expectations, motivators and barriers when designing interventions for the different levels of prevention (i.e. treatment $v$. weight gain prevention), as well as for different age and socio-economic groups.

\section{Weight-loss expectations}

Despite over $50 \%$ of the sample being a healthy weight, almost $80 \%$ of the young women surveyed were unhappy at their current weight, which increased with higher BMI to over $90 \%$ among overweight and obese women. Of the women who wanted to change their weight, most wanted to lose approximately $8 \mathrm{~kg}$ or $12 \%$ of their current body weight. Although this level of desired weight loss is substantially lower than reported in previous studies of adults and young women, where weight losses of 21-28\% were needed to meet their desired weight ${ }^{(17-20,35,56)}$, the expectations of young women in the current sample still exceeded clinical guideline recommendations of 5 to $10 \%$ initial weight loss ${ }^{(15,16)}$.

\section{Motivations for weight change}

Our findings are consistent with previous studies that have reported feeling better about oneself and improved health as primary motivators for attempting weight loss ${ }^{(17,21,30,36-39)}$. Surprisingly, in the current study improving appearance was one of the least important motivations reported by young women, with over half of respondents ranking it as the least important reason (ranked fifth or sixth out of six reasons). This finding is in contrast to previous research where young women reported appearance as a key motivation for attempting weight loss ${ }^{(17,39)}$.

\section{Perceived factors influencing weight management}

The perceived factors influencing weight management in the current sample support earlier research that lack of motivation $^{(40,42,44,45)}$ and time ${ }^{(40-43)}$ are major influences. The most common perceived factors relating to physical activity and eating habits were the same, which highlights the importance of addressing these factors in contemporary weight management interventions and public health messaging.
Differences by age, BMI and socio-economic status The secondary aim of the current study highlighted a number of differences for weight-loss expectations, key motivators for weight change and perceived factors influencing weight management by age, BMI, marital status, income and education. Many of the findings were as expected; for example, our findings were consistent with previous studies in young women, with larger weight-loss expectations reported in line with higher $\mathrm{BMI}^{(35,56)}$. However, other findings were novel. For example, an earlier study in young Australian women ${ }^{(46)}$ reported no differences by household composition, education or BMI for factors influencing weight management. In contrast, we found many of the healthy eating- and physical activity-related factors reported to influence weight management differed by age, BMI, marital status, education and income level. For example, consistent with previous research ${ }^{(44)}$, women earning lower incomes were more likely to perceive a greater number of factors to influence their weight management, including access, skills, knowledge and cost of healthy eating.

\section{Strengths and limitations}

Strengths of the current study include that it provides data from a large contemporary sample ( $n$ 620) that is generally representative of young women. Limitations include that all survey items were self-reported and are therefore subject to bias. Self-reported weight and height were used to calculate BMI and weight change to achieve ideal weight. However, a recent study has demonstrated the validity of online self-report of height and weight by young adults ${ }^{(57)}$. The item used to evaluate young women's motivations for weight change was limited to six predetermined potential motivators for weight change based on a review of previous research of weight-loss expectations. It is possible that the survey respondents had other primary motivators for wanting to change their weight that were not captured by this survey and that may need to be considered in the development of weight management interventions for young women. In addition, the six predetermined motivators were focused on potential benefits of weight change (i.e. gain-framed); the inclusion of loss-framed motivators that considered the potential disadvantages of weight change may have provided a better understanding of the relative ranking of the gain-framed motivators. A further limitation of the survey was the use of a dichotomous measure of weight satisfaction, as it provides no indication of respondents' degree of satisfaction with their current weight. Such an item would have provided greater insight into the level of weight satisfaction among young women, with potentially other differences by weight and sociodemographic status shown. The recruitment materials specifically requested young women to participate in a survey to help design a tailored weight-loss programme. Selection bias may therefore be an issue, with more women participating who 
are interested in weight control or going in the draw to receive a desired prize. This may have influenced the reported expectations, motivations and perceived factors influencing weight management, and hence the results may not be generalizable to all young women. Although the sample was largely representative of the young Australian female population, as recruitment was initiated in the university setting and used convenience and snowball sampling, the sample had higher proportions of women with higher education levels and those who were overweight. The survey did not establish current occupation, study habits or living arrangements (e.g. with parents, on the university campus, shared house) that may have addressed reasons for lower incomes and further explained responses for factors influencing weight management. In addition, the definition of 'young' women (18-30 years) used in the study is different from other research, where young adulthood is defined as 18-35 years of age, as per the US National Institutes of Health ${ }^{(58)}$. Finally, the present study included young females only, and therefore does not determine the weight expectations, motivations for weight change or factors that influence weight management for males. Given young males are also at high risk of weight gain, future research must capture these factors for young males also and compare with our findings in young women.

\section{Study implications}

The current findings provide insight into areas to target in weight management interventions for young women, through addressing expectations, motivations and perceived factors influencing weight management in this group. This includes potential differences in intervention design by level of prevention (e.g. obesity treatment $v$. weight gain prevention) due to notable differences by BMI, as well as potential tailoring of intervention messages to different age and socio-economic status groups. More specifically:

- Young women may benefit from education about realistic weight-change expectations upon commencement of a weight management intervention (e.g. focus on achieving and maintaining a realistic weight loss of $5-10 \%$ of initial weight). We know that young women have high levels of drop-out from traditional weight management interventions ${ }^{(10)}$ and research suggests that individuals with higher weight-loss expectations at enrolment are more likely to drop out ${ }^{(17)}$. So by addressing weight-loss expectations at the commencement of the programme, retention and engagement rates may be positively influenced. This is of particular importance for weight-loss interventions that target obese individuals, who have the most unrealistic expectations for the level of weight change they wish to achieve.

- Interventions promoted as 'weight gain prevention' programmes may not be of interest to young women, as the majority, including those of a healthy weight, report wanting to change their current weight. This is consistent with previous research with college students which found less than half of normal-weight female students were interested in participating in a programme that was designed to help them remain at their current weight ${ }^{(59)}$. Therefore, interventions that aim to prevent weight gain in this target group may need to promote other potential benefits of the programme to engage young women (e.g. improving physical activity levels, eating habits and/or general health and well-being), but further formative research is required to confirm this.

- Many young women are motivated to change their weight due to potential improvements to their health and general well-being. Therefore weight gain prevention interventions designed for all young women should tailor their intervention messages to these primary motivators. More specifically, obese individuals report higher rates of motivation to change their weight due to health-related reasons. Therefore, weight-loss interventions that are specifically designed for this population group should emphasize the health-related benefits of behaviour change and/or weight loss to engage participants.

- Interventions should also address the main factors influencing young women's ability to manage their weight, including motivation, time constraints and cost. Therefore behavioural strategies that engage and motivate young women to lead a healthy lifestyle, while providing ideas to increase physical activity that are both time- and cost-effective and the skills to plan, purchase and prepare quick, affordable and healthy meals, should be incorporated into weight gain prevention interventions for all young women. These strategies should aim to address time constraints experienced by young women due to work commitments, by providing practical tips to achieve work/life balance.

- Providing opportunities for social support (e.g. group meetings, online discussion forums or social networking) within weight-loss programmes for young obese women appears to be of particular importance, as lack of support from existing support networks (e.g. family, friends) is a more pronounced barrier to physical activity and healthy eating in this target group.

- Overall, interventions for weight gain prevention or obesity treatment must consider the influence of age and socio-economic status on the factors that may influence behaviours (e.g. low-income individuals finding the cost or access to healthy foods a barrier; single women, 18-24-year-olds and those of lower income reporting skills to plan, shop and prepare healthy foods as a barrier; 18-24-year-olds reporting lack of information about healthy eating as a barrier). This could be addressed through the design of interventions that consider all potential influences on behaviours and allow individuals to participate and/or contribute to 
those elements of most interest (e.g. weight management interventions for young women would need to address healthy eating guidelines, accessibility of healthy foods, meal planning and preparation of simple, inexpensive healthy meals). Alternatively, this could be addressed through the use of intervention delivery modes that can be tailored to young women's individual needs, in a cost-efficient manner (e.g. eHealth technologies).

\section{Acknowledgements}

Financial support: This work was supported by the Priority Research Centre in Physical Activity and Nutrition, University of Newcastle (M.J.H.). The current analysis was undertaken as part requirement for the Bachelor of Nutrition and Dietetics (Honours) degree, School of Health Sciences, University of Newcastle, Australia (T.J.H.). M.J.H. is supported by a National Heart Foundation Postdoctoral Research Fellowship 2014-2016 (Award ID 100177). The funders had no role in the design, analysis or writing of this article. Conflict of interest: None. Authorship: M.J.H., C.E.C., P.J.M. and R.C. were responsible for the study design. T.J.H. conducted the statistical analysis with the assistance of M.J.H. T.J.H. drafted the initial manuscript. All authors contributed to interpreting the results, reviewing, editing and approving the submitted manuscript. Ethics of human subject participation: This study was conducted according to the guidelines laid down in the Declaration of Helsinki and all procedures involving human subjects were approved by the Human Research Ethics Committee of the University of Newcastle, Australia (H-2012-0208). Informed consent was obtained from all participants.

\section{Supplementary material}

To view supplementary material for this article, please visit http://dx.doi.org/10.1017/S1368980015000993

\section{References}

1. Adamson L, Brown W, Byles J et al. (2007) Women's Weight: Findings from the Australian Longitudinal Study on Women's Health. Australia: The University of Newcastle and The University of Queensland.

2. Tanamas SK, Magliano DJ, Lynch B et al. (2013) AusDiab 2012. The Australian Diabetes, Obesity and Lifestyle Study. Melbourne: Baker IDI Heart and Diabetes Institute.

3. Lewis C, Jacobs DR Jr, McCreath H et al. (2000) Weight gain continues in the 1990s: 10-year trends in weight and overweight from the CARDIA Study. Am J Epidemiol 151, $1172-1181$.

4. Carpenter K, Hasin D, Allison D et al. (2000) Relationships between obesity and DSM-IV major depressive disorder, suicide ideation, and suicide attempts: results from a general population study. Am J Public Health 90, 251-257.
5. Kulie T, Slattengren A, Redmer J et al. (2011) Obesity and women's health: an evidence-based review. J Am Board Fam Med 24, 75-85.

6. Ryan D (2007) Obesity in women: a life cycle of medical risk. Int J Obes (Lond) 31, Suppl. 2, S3-S7.

7. Colditz G, Willett W, Rotnitzky A et al. (1995) Weight gain as a risk factor for clinical diabetes mellitus in women. Ann Intern Med 122, 481-486.

8. Willett W, Manson J, Stampfer M et al. (1995) Weight, weight change, and coronary heart disease in women. Risk within the 'normal' weight range. JAMA 273, 461-465.

9. Bray G (2004) Medical consequences of obesity. J Clin Endrocrinol Metab 89, 2583-2589.

10. LaRose J, Gorin A, Raynor H et al. (2009) Are standard behavioural weight loss programs effective for young adults? Int J Obes (Lond) 33, 1374-1380.

11. Hebden L, Chey T \& Allman-Farinelli M (2012) Lifestyle interventions for preventing weight gain in young adults: a systematic review and meta-analysis. Obes Rev 13, 692-710.

12. Laska M, Pelletier J, Larson N et al. (2012) Interventions for weight gain prevention during the transition to young adulthood: a review of the literature. J Adolesc Health 50, 324-333.

13. Poobalan A, Aucott L, Precious E et al. (2010) Weight loss interventions in young people (18 to 25 year olds): a systematic review. Obes Rev 11, 580-592.

14. Hutchesson MJ, Hulst J \& Collins CE (2013) Weight management interventions targeting young women: a systematic review. J Acad Nutr Diet 113, 795-802.

15. American Dietetic Association (2009) Position of the American Dietetic Association: weight management. $J \mathrm{Am}$ Diet Assoc 109, 330-346.

16. National Health and Medical Research Council (2013) Clinical Practice Guidelines for the Management of Overweight and Obesity in Adults. Melbourne: NHMRC.

17. Dalle Grave R, Calugi S, Molinari E et al. (2005) Weight loss expectations in obese patients and treatment attrition: an observational multicenter study. Obesity (Silver Spring) 13, 1961-1969.

18. Fabricatore A, Wadden T, Womble L et al. (2007) The role of patients' expectations and goals in the behavioural and pharmacological treatment of obesity. Int J Obes (Lond) $\mathbf{3 1}$, 1739-1745.

19. Linde J, Jeffery R, Levy R et al. (2005) Weight loss goals and treatment outcomes among overweight men and women enrolled in weight loss trial. Int J Obes (Lond) 29, 1002-1005.

20. Wadden T, Womble L, Sarwer D et al. (2003) Great expectations: 'I'm losing $25 \%$ of my weight no matter what you say'. J Consult Clin Psychol 71, 1084-1089.

21. Foster G, Wadden T, Vogt R et al. (1997) What is a reasonable weight loss? Patients' expectations and evaluations of obesity treatment outcomes. J Consult Clin Psychol 65, 79-85.

22. Jeffery R, Wing R \& Mayer R (1998) Are smaller weight losses or more achievable weight loss goals better in the long term for obese patients? J Consult Clin Psychol 66, 641-645.

23. Teixeira P, Going S, Houtkooper L et al. (2002) Weight loss readiness in middle-aged women: psychosocial predictors of success for behavioral weight reduction. J Behav Med $\mathbf{2 5}$, 499-523.

24. Foster G, Wadden T, Phelan S et al. (2001) Obese patients' perceptions of treatment outcomes and the factors that influence them. Arch Intern Med 161, 2133-2139.

25. Neil P, Smith C, Foster G et al. (2000) The perceived relative worth of reaching and maintaining goal weight. Int $J$ Obes Relat Metab Disord 24, 1069-1076.

26. Foster G, Phelan S, Wadden T et al. (2004) Promoting more modest weight losses: a pilot study. Obesity (Silver Spring) 12, 1271-1277. 
27. Dutton G, Perri M, Dancer-Brown M et al. (2010) Weight loss goals of patients in a health maintenance organization. Eat Behav 11, 74-78.

28. Provencher V, Begin C, Gagnon-Girouard M et al. (2007) Defined weight expectations in overweight women: anthropometrical, psychological and eating behavioral correlates. Int J Obes (Lond) 31, 1731-1738.

29. Linde J, Jeffery R, Finch E et al. (2004) Are unrealistic weight loss goals associated with outcomes for overweight women? Obesity (Silver Spring) 12, 569-576.

30. Crawford D, Owen N, Broom D et al. (1998) Weight-control practices of adults in a rural community. Aust N Z J Public Health 2, 73-79.

31. Linné Y, Hemmingsson E, Adolfsson B et al. (2002) Patient expectations of obesity treatment - the experience from a day-care unit. Int J Obes Relat Metab Disord 26, 739-741.

32. Williamson D, Serdula M, Anda R et al. (1992) Weight loss attempts in adults: goals, duration, and rate of weight loss. Am J Public Health 82, 1251-1257.

33. Wamsteker E, Geenen R, Zelissen P et al. (2009) Unrealistic weight-loss goals among obese patients are associated with age and causal attributions. I Am Diet Assoc 109, 1903-1908.

34. Crawford D \& Campbell K (1999) Lay definitions of ideal weight and overweight. Int J Obes Relat Metab Disord 23, 738-745.

35. Siervo M, Montagnese C, Muscariello E et al. (2014) Weight loss expectations and body dissatisfaction in young women attempting to lose weight. J Hum Nutr Diet 27, 84-89.

36. Kwan S (2009) Competing motivational discourses for weight loss: means to ends and the nexus of beauty and health. Qual Health Res 19, 1223-1233.

37. Green K, Cameron R, Polivy J et al. (1997) Weight dissatisfaction and weight loss attempts among Canadian adults. CMAJ 157, Suppl. 1, S17-S25.

38. Striegel-Moore R, Wilfrey D, Caldwell M et al. (1996) Weight-related attitudes and behaviors of women who diet to lose weight: a comparison of black dieters and white dieters. Obesity (Silver Spring) 4, 109-116.

39. LaRose J, Leahey T, Hill J et al. (2013) Differences in motivations and weight loss behaviors in young adults and older adults in the National Weight Control Registry. Obesity (Silver Spring) 21, 449-453.

40. Booth M, Bauman A, Owen N et al. (1997) Physical activity preferences, preferred sources of assistance, and perceived barriers to increased activity among physically inactive Australians. Prev Med 26, 131-137.

41. Lappalainen R, Saba A, Holm L et al. (1997) Difficulties in trying to eat healthier: descriptive analysis of perceived barriers for healthy eating. Eur J Clin Nutr 51, Suppl. 2, S35-S40.

42. Johnson C, Corrigan S, Dubbert P et al. (1990) Perceived barriers to exercise and weight control practices in community women. Women Health 16, 177-191.
43. Kearney J \& McElhone S (1999) Perceived barriers in trying to eat healthier - results of a pan-EU consumer attitudinal survey. Br J Nutr 81, Suppl. 2, S133-S137.

44. Siu J, Giskes K \& Turrell G (2011) Socio-economic differences in weight-control behaviours and barriers to weight control. Public Health Nutr 14, 1768-1778.

45. Ball K, Crawford D \& Owen N (2000) Too fat to exercise? Obesity as a barrier to physical activity. Aust $N Z J$ Public Health 24, 331-333.

46. Sutjahjo S, Ball K, Warren N et al. (2004) Perceived personal, social and environmental barriers to weight maintenance among young women: a community survey. Int J Behav Nutr Phys Act 1, 15.

47. Australian Bureau of Statistics (2013) 3301.0 - Births, Australia, 2013. Canberra: ABS.

48. Australian Bureau of Statistics (2011) Information Paper: Census of Population and Housing Nature and Content Australia. Canberra: ABS

49. Arnett J (2000) Emerging adulthood. A theory of development from the late teens through the twenties. Am Psychol 55, 46-80.

50. World Health Organization (2000) Obesity: Preventing and Managing the Global Epidemic. Report of a WHO Consultation. WHO Technical Report Series no. 894. Geneva: WHO.

51. Miller Y (2003) Recommendations for the Truncation of Body Mass Index in Population Data. Liverpool: NSW Centre for Physical Activity and Health.

52. Australian Bureau of Statistics (2012) 6227.0 - Education and Work, Australia, May 2012 - Data Cube Only. Canberra: ABS.

53. Australian Bureau of Statistics (2013) 6310.0 - Government Benefits, Taxes, and Household Income, Australia. Canberra: ABS.

54. Australian Bureau of Statistics (2013) 2011 Census QuickStats: Australia. Canberra: ABS.

55. Australian Bureau of Statistics (2013) 4364.0.55.003 Australian Health Survey: Updated Results, 2011-2012. Canberra: ABS.

56. Malinauskas B, Raedeke T, Aeby V et al. (2006) Dieting practices, weight perceptions, and body composition: a comparison of normal weight, overweight, and obese college females. Nutr J 5, 11.

57. Pursey K, Burrows TL, Stanwell P et al. (2014) How accurate is web-based self-reported height, weight, and body mass index in young adults? J Med Internet Res 16, e4.

58. Lytle LA, Svetkey LP, Patrick K et al. (2014) The EARLY trials: a consortium of studies targeting weight control in young adults. Transl Behav Med 4, 304-313.

59. LaRose J, Gorin A, Clarke M et al. (2011) Beliefs about weight gain among young adults: potential challenges to prevention. Obesity (Silver Spring) 19, 1901-1904. 